DOI: $10.31249 / \mathrm{rsm} / 2018.02 .08$

\title{
H.В. Попова
}

\section{ПЕРСПЕКТИВЫ РАЗВИТИЯ ОБЪЕАИНЕНИЯ “БРИКС ПАЮС"}

Аннотация. В статье автор анализирует возможности и перспективы реализачии нового формата БРИКС+. Обоснована идея, что дальнейшее расширение БРИКС может идти не по линии приглашения новых членов, а по линии взаимодействия на основе уже созданных альянсов, «интеграции интеграиий». Сделан вывод о том, что региональные объединения, в которых страны БРИКС играют главенствуюшую роль, могли бы стать фундаментом платформы БРИКС $+u$ в дальнейшем сформировать периметр внеамериканской зоны взаимодействия. Рассматривается роль БРИКС в качестве медиатора и идейного вдохновителя взаимодействий ряда партнерских интеграционных объединений.

Ключевые слова: БРИКС + , неформальное объединение, многополярность, внеамериканская зона взаимодействия, санкиионная политика.

Попова Наталья Валерьевна - соискатель кафедры глобалистики факультета глобальных процессов МГУ имени М.В. Ломоносова, главный специалист Управления профессиональной ориентации и работы с талантливой молодежью МГУ имени М.В. Ломоносова. E-mail: Natalia-kp@mail.ru

N.V. Popova. Prospects for the Development of the «BRICS Plus» Association

Abstract. Analyzing the prospects of executing the new BRICS + format, the author argues that the further expansion of BRICS should not progress by way of inviting new members. Rather the organization should deepen co-operation within the already established alliances, practicing the so called «integration of integrations». Pursuing this policy, this model of integration could become a platform for BRICS+ and eventually form a perimeter of a non-American zone of economic activities in the world.

Keywords: BRICS+, an informal association, multipolar world, non-American zone of interaction, sanctions policy. 


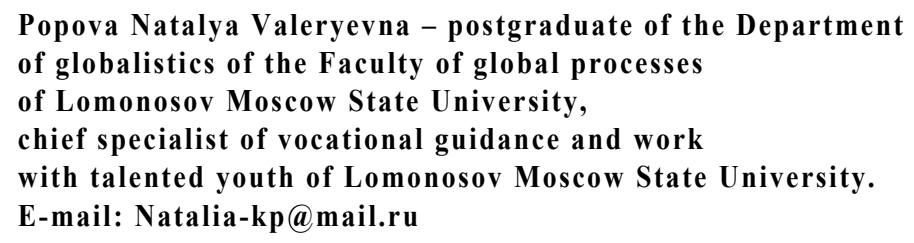

Формально БРИК существует с 2001 г., когда аналитик банка Goldman Sachs придумал данный акроним для объединения быстрорастущих экономик. Хотя есть и другая версия: еще в 1998 г. премьер-министр России Е.М. Примаков обозначил важность взаимодействия России с Индией и Китаем, и тем самым наметил контуры организации РИК. Чуть позже, в том же 1998 г., посещая Бразилию, Примаков подписал соглашение о сотрудничестве, что дало право России считать себя основоположником объединения, смыслом которого является обеспечение справедливого миропорядка и учета интересов развивающихся экономик.

Официальным стартом этого неформального объединения можно считать 2006 г., когда в рамках Петербургского экономического форума главы четыpex государств - России, Индии, Китая и Бразилии - договорились о его создании.

Несмотря на достаточно долгий срок функционирования БРИКС, его актуальность и востребованность в глобальной политике только растет. Причем если в экономической сфере у БРИКС есть ряд проблем, например замедление темпов роста экономик его стран и недостаточной ориентированности членов объединения на внутреннее торговое и инвестиционное взаимодействие, то важность объединения с точки зрения происходящих политических процессов сложно переоценить. Согласно исследованиям, ведущимся на факультете глобальных процессов МГУ им. М.В. Ломоносова, мы вступили в транзитарный период, отмеченный переходом от однополярной модели к многополярности. БРИКС в этом процессе занимает важное место как глобальный актор нового геополитического ландшафта, претендующий на статус центра силы [6, с. 25].

Выступая на 70-й сессии Генеральной Ассамблеи ООН, Президент РФ В.В. Путин отметил, что политика эксклюзивности должна завершиться [1]. Это значит, что доминирование и эксклюзивность решений существующих экономических и политических объединений должно стать менее выраженным и дать место на мировой арене другим объединениям, в том числе без участия или влияния США.

Прогнозируется, что маятник глобальной системы, двигаясь в сторону многополярности, задержится в равновесной точке, т.е. точке биполярности, где существующему центру силы в лице США будет противопоставлен Китай. Если Соединенные Штаты, укрепляя свое доминирование в глобальном 
мире, всегда опирались на Европейский союз и других многочисленных партнеров, то Китай может рассчитывать на поддержку стран - членов БРИКС и ШОС, совокупное геополитическое влияние которых составляет внеамериканскую зону взаимодействия. И надо признать, что в объединении БРИКС Китай занимает лидирующую позицию. Более того, события последнего года показывают, что Китай уже готов примерить на себя статус нового центра силы. Примечательной в этом плане стала программная речь Си Цзиньпина, с которой он выступил на экономическом форуме в Давосе в январе 2017 г. Аналитики отмечают: Китай осваивается в новой роли глобального экономического лидера, которую освобождают для него США. Си Цзиньпин высказался в защиту свободы торговли и против новой волны протекционизма, которую связывают с новой американской администрацией. Одновременно - в поддержку позиции Си Цзиньпина - Госсовет КНР объявил об открытии для иностранных инвесторов доступа в ключевые отрасли китайской экономики. Визит лидера КНР в Давос фактически означает заявку на смену глобального лидерства [2].

Позиция же нынешнего мирового гегемона, США, с приходом к власти нового президента Трампа достаточно быстро смещается с глобального доминирования в сторону фокусировки на внутристрановых проблемах по принципу «America First». Символичным стало выступление Трампа на том же Давосском экономическом форуме год спустя после визита туда Си Цзиньпина. Он еще раз подчеркнул приверженность данному принципу. По мнению главы Совета по международным отношениям (США) Ричарда Хааса, Трамп еще раз дал понять, что роль международного лидера обходится США слишком дорого [10].

Все вышесказанное свидетельствует о том, что точка бифуркации в отказе от однополярной модели уже пройдена. Китай, осваиваясь в новой роли, наращивает круг партнеров. Именно Китай, являясь принимающей стороной девятого саммита БРИКС в сентябре 2017 г., предложил реформаторскую инициативу «БРИКС+». Ранее, начиная с саммита в Дурбане в 2013 г., страны-председатели также традиционно приглашали к участию некоторые дружественные государства из своего региона, но именно Китай предложил идею дополнить БРИКС постояннылм кругом стран-партнеров.

Китайская Народная Республика на правах председателя БРИКС в 2017 г. пригласила на девятый саммит Мексику, Гвинею, Таиланд и Таджикистан. Это весьма интересный выбор, который стоит проанализировать. Прежде всего бросается в глаза, что это пять различных регионов: Африка, Латинская Америка, Юго-Восточная и Центральная Азия. Конечно, потенциал этих стран неравнозначен, тем не менее важен сам факт закрепления влияния БРИКС в различных регионах. Безусловно, помимо политического веса Китаю важны новые рынки сбыта, и в этом плане выбор стран в формате 
БРИКС+ также оправдан. Мексика как потенциальный импортер интересна не только Китаю, но и всем странам БРИКС. Таджикистан хотя и значительно уступает по экономической мощи той же Мексике, тем не менее может рассматриваться как один из младших партнеров Китая, который стоит держать в круге своих интересов. Таиланд, как, впрочем, и вся Юго-Восточная Азия, интересны Китаю как непосредственному региональному лидеру. Гвинея, как и весь Африканский континент, значимы для Китая как экспортная площадка и как импортер сельскохозяйственной продукции.

Но в целом первостепенная роль БРИКС+ все-таки в создании ареала политически дружественных стран, обеспечивающих опору Китаю в грядущей роли нового центра силы. Сама площадка БРИКС в ныне существующем виде уже носит в своей основе принцип «интеграции интеграций», так как каждая страна в этом объединении - уже региональный лидер, ведущая экономика на своем континенте или в своем субрегионе. Более того, для каждой страны в БРИКС существуют свои региональные объединения, в которых она занимает лидерские позиции:

- Россия - в Евразийском экономическом союзе;

- Бразилия - в МЕРКОСУР;

- ЮАР - в Африканском Союзе (АС), в Сообществе развития Юга Африки (САДК);

- Индия - в Ассоциации регионального сотрудничества Южной Азии (СААРК);

- Китай - в Шанхайской организации сотрудничества (ШОС), в объединениях АСЕАН+3 и АСЕАН+6.

Таким образом, представляется весьма логичным, что дальнейшее расширение БРИКС может идти не по линии приглашения новых членов, а по линии взаимодействия на основе уже созданных альянсов, «интеграции интеграций». Региональные объединения, в которых страны БРИКС играют главенствующую роль, могли бы стать фундаментом платформы БРИКС+.

Движения в сторону взаимодействий региональных блоков уже начались, стоит лишь вспомнить меморандум о взаимопонимании МЕРКОСУР и ЕАС, торговое соглашение МЕРКОСУР и САДК.

Для стран БРИКС критически важно быть медиатором и идейным вдохновителем таких взаимодействий по двум причинам: во-первых, БРИКС является первым объединением, в полной мере осознавшим необходимость сотрудничества с региональными блоками и включившим такое взаимодействие в свою повестку. О.Г. Леонова отмечает, что тенденция к так называемой глокализации (т.е. сохранения и развития региональных отличий на фоне продолжающейся глобализации) обусловлена интенсивными интеграционными процессами, которые идут во всем мире и в результате которых 
происходит объединение стран в региональные системы и складывание макрорегионов [7, с. 59-66]. Во-вторых, для каждой страны - участницы БРИКС свой региональный проект с точки зрения торгового взаимодействия является приоритетным, и в связи с этим для укрепления экономических основ БРИКС крайне важно включать региональные блоки в периметр объединения.

Что касается возможных путей работы площадки БРИКС+, по предложению Я.Д. Лисовика (программного директора Фонда развития и поддержки Международного дискуссионного клуба «Валдай», главного экономиста Евразийского Банка Развития) главы пяти основных региональных блоков, а также соответствующие организации развития могли бы встречаться на саммитах БРИКС для анализа вопросов интеграции и установления целей развития и сотрудничества на будущее. В качестве альтернативы каждая страна, принимающая у себя саммит БРИКС, может приглашать представителей своего регионального блока для установления более тесного партнерства между ним и странами БРИКС.

Итоговый документ девятого саммита, первого в формате зарождающейся модели БРИКС+, - Сямэньская Декларация, подчеркивает роль БРИКС как многостороннего и внеидеологического механизма, призванного вывести развивающиеся рынки на видное место в глобальном управлении. Безусловно, такой подход повышает привлекательность БРИКС для других стран. В документе первостепенная роль отведена выработке и внедрению более справедливых правил международного экономического взаимодействия, свободного от излишнего протекционизма и прочих искусственных барьеров в торговле, наподобие экономических санкций как инструмента политического давления. «В настоящее время в мире происходят глубокие и комплексные изменения, такие условия повышают важность сотрудничества в рамках БРИКС... Наши пять стран должны играть более активную роль в системе глобального управления, без нашего участия многие мировые вызовы не могут быть эффективно разрешены», - заявил китайский лидер [3].

Пожалуй, стоит подробнее остановиться на использовании санкций как дискриминационной меры, влияющей на геополитическое устройство, векторы развития БРИКС и перспективу укрепления внеамериканской зоны взаимодействия. Характерной чертой санкционной политики всегда является ее широкое воздействие, маховик санкций раскручивается не только против страны - непосредственного объекта, но задевает интересы широкого круга партнеров и в конечном итоге страну-инициатора.

Рассмотрим, к примеру, эффект санкций США в отношении России с точки зрения влияния на мировую политическую систему. 
Как отметил глава ВТБ Андрей Костин на Всемирном экономическом форуме в Давосе, США при помощи санкций добиваются смены политического режима в России.

Павел Салин, директор Центра политологических исследований Финансового университета, считает, что смена власти в стране была целью первого пакета санкций в 2014 г. Однако эти расчеты не оправдались, наоборот, народ в патриотичном порыве даже объединился вокруг своего президента. Цель новых санкций - поставить российские элиты перед жестким выбором. Многие из них все это время, как говорится, жили на два дома. Они поддерживали президента и одновременно хотели стать частью западного истеблишмента. Их заставят выбрать одну сторону. Главная задача - расколоть российские элиты. Так ими будет проще манипулировать [8].

Заместитель председателя Комитета Совета Федерации по международным делам Андрей Климов напоминает, что еще в 2003 г. Бушем-младшим было названо 50 государств, включая Россию, в которых, по их мнению, нужно было изменить политическую систему, под это выделялись деньги и принимались законы [4]. Таким образом, не стоит забывать, что действия США по введению санкций против России являются частью стратегической политики Америки по обеспечению комфортного для своих национальных интересов глобального порядка. И во имя достижения этой цели считается возможным признать нелегитимное правительство, пришедшее без демократических выборов в ходе государственного переворота, и поддержать их территориальные притязания.

Но санкции меняют глобальный порядок, и далеко не всегда в ту сторону, на которую рассчитывал инициатор. У санкционной политики наметился незапланированный «побочный» эффект в виде перехода к многополярному мироустройству. Так, наблюдая за развитием ограничительной политики США в отношении России, финансовые и политические институты других стран, де-юре не вовлеченных в этот конфликт, невольно примеряют на себя подобную ситуацию с учетом фактической зависимости национальных экономик от действий страны-гегемона и понимания расхождений в номинальных и реальных причинах введения санкций. Таким образом, тревожность других стран по поводу возможности попадания в аналогичную ситуацию в случае, если обеспечение национальных интересов страны и политический курс правительства будет идти вразрез с интересами США, нарастает. Ответом на этот вызов для некоторых стран видится возможный уход от долларовой зависимости, расширение пула резервных валют и переход на параллельные системы расчетов.

Уже с 2015 г. Россия обсуждает с Китаем вопрос создания альтернативной финансовой системы для стран БРИКС. Одним из возможных решений может стать также и переход на расчеты в криптовалюте. Для США это озна- 
чает резкое ослабление доллара, что идет вразрез с их традиционным курсом укрепления национальной валюты. Уже сейчас прослеживается весьма интересная тенденция ослабления доллара на фоне хороших экономических показателей. На конец января 2018 г. доллар достиг многолетних минимумов по всему миру. Министр финансов США Стивен Мнучин обосновывает ослабление доллара ростом экономики и отчасти это действительно так. Однако можно представить, что будет с долларом, если часть финансовых институтов других стран начнут постепенную де-долларизацию.

Очень символично, что о возможном крахе долларовой системы сказал в своем выступлении Джим О'Нил, создатель термина БРИК, в ходе своего выступления на нефтяной конференции «ADIPEC-2017». Он отметил, что статус доллара как самой мощной валюты подвергается испытаниям уже не одно десятилетие, однако контракты на основе американской валюты продолжают преобладать на мировых рынках. Хотя в последние месяцы инвесторы все больше говорят о том, что Китай готовится сделать решительный шаг для прекращения доминирование доллара (перейти на юань при закупке нефти у Саудовской Аравии и ряда других поставщиков, а также запустить нефтяные фьючерсы в китайской валюте) [9]. Безусловно, постепенный уход от доллара будет в первую очередь обусловлен естественными геополитическими причинами, развитием биполярной системы и через нее мультиполярности. Однако данные тенденции могут быть усилены проактивным желанием стран защитить свои национальные интересы от диктата страны-доминанта.

Сразу после принятия обеими палатами Конгресса США пакета новых санкций против России замглавы МИД РФ Сергей Рябков выступил с серьезным предупреждением в адрес Вашингтона. «Санкции США против России будут лишь подталкивать РФ к созданию альтернативной экономической системы, при которой доллары в расчетах будут не нужны», - заявил российский дипломат [5].

В противостоянии санкционному режиму Россия достигла весьма серьезных результатов. Политическая система стабильна, а о восстановлении экономики говорит тот факт, что 26 января 2018 г. Международное агентство Moody`s улучшило прогноз суверенного рейтинга России со «стабильного» на «позитивный». Основными факторами для изменения прогноза по рейтингу стали «рост доказательств институциональной силы», а также то, что «макроэкономика России хорошо справилась с шоковыми ценами на нефть и с санкциями, введенными к настоящему времени». «Вместе с этим возросло доказательство экономической и фискальной устойчивости, которая снижает уязвимость России к дальнейшим внешним потрясениям от геополитической напряженности или от возобновления снижения цен на нефть», - говорится в сообщении [11]. 
Выступая на девятом саммите БРИКС, Президент России В.В. Путин призвал быстрее переходить на кредитование в национальных валютах БРИКС, создать фонд облигаций БРИКС и интегрировать рынки капитала государств «пятерки». Облигации в национальных валютах сделают более доступным капитал банка БРИКС, что важно для финансирования экономического роста стран-участниц и нейтрализации санкционного давления США.

С учетом непростой международной политической обстановки представляется очевидной актуальность объединения БРИКС+ как внеамериканской зоны взаимодействия и, более того, расширение неформального партнерства за счет взаимодействия со странами исламского мира. На первый взгляд, предложение рассмотреть страны Персидского залива в качестве возможных партнеров по диалогу представляется безосновательным, но при детальном анализе оснований общий базис находится, и лежит он в плоскости ценностных ориентиров.

\section{Библиография}

1. Владимир Путин принял участие в пленарном заседании юбилейной 70-й сессии Генеральной Ассамблеи ООН в Нью-Йорке // Официальные сетевые ресурсы Президента России. 2015. 28 сентября. URL: http://www.kremlin.ru/events/president/news/50385 (Дата обращения: 06.02.2018.)

2. Давос встречает нового глобального лидера. Поднебесная становится локомотивом идей для мировой экономики // Независимая газета. 2017. 13 января. URL: http://www.ng.ru/ editorial/2017-01-13/2_6902_red.html (Дата обращения: 06.02.2018.)

3. Девятый саммит БРИКС: Заявления о дружбе, открытости и сотрудничестве // РИА Новости. 2017. 5 сентября. URL: https://ria.ru/world/20170905/1501845256.html (Дата обращения: 06.02.2018.)

4. Если американцы отключат Swift, они пересядут с «Боинга» на метлу // EurAsia Daily. 2018. 27 января. https://eadaily.com/ru/news/2018/01/27/esli-amerikancy-otklyuchat-swift-oniperesyadut-s-boinga-na-metlu-senator (Дата обращения: 06.02.2018.)

5. Крах гегемонии США: Страны БРИКС все же откажутся от доллара // Pravda.Ru. 2017. 3 августа. URL: https://www.pravda.ru/world/03-08-2017/1344206-gegemony_usa-0/ (Дата обращения: 06.02.2018.)

6. Леонова О.Г. БРИКС - внеамериканская зона взаимодействия // Обозреватель. 2015. № 1. C. $25-33$.

7. Леонова О.Г. Глобальная регионализация как феномен развития глобального мира // Век глобализации. 2013. № 1. С. 59-66.

8. Цель новых американских санкций - смена власти в России // Комсомольская правда. 2018. 24 января. URL: https://www.kp.ru/daily/26784/3819591/ (Дата обращения: 06.02.2018.)

9. Экономист: Китай готовит решительный шаг для свержения доллара // Эксперт. 2018. № 6. URL: http://expert.ru/2017/11/20/onil/ (Дата обращения: 06.02.2018.)

10. Haass R. What the Global Elite Can Learn From Donald Trump // Time. 2018. Jan. 25. URL: http://time.com/5118038/global-elite-donald-trump/ (Дата обращения: 06.02.2018.)

11. Moody's улучшило прогноз по кредитному рейтингу России до «позитивного» // РБК. 2018. 26 января. URL: https://www.rbc.ru/economics/26/01/2018/5a6a575a9a7947595acd7712 (Дата обращения: 06.02.2018.) 


\section{РОССИЯ И МИР В ХХІ ВЕКЕ}

\section{References}

Cel' novyh amerikanskih sankcij - smena vlasti v Rossii // Komsomol'skaja pravda. 2018. Jan. 24. URL: https://www.kp.ru/daily/26784/3819591/ (Data obrashhenija: 06.02.2018.)

Davos vstrechaet novogo global'nogo lidera. Podnebesnaja stanovitsja lokomotivom idej dlja mirovoj jekonomiki // Nezavisimaja gazeta. 2017. Jan. 13. URL: http://www.ng.ru/editorial/2017-0113/2_6902_red.html (Data obrashhenija: 06.02.2018.)

Devjatyj sammit BRIKS: zajavlenija o druzhbe, otkrytosti i sotrudnichestve // RIA Novosti. 2017. Sept. 5. URL: https://ria.ru/world/20170905/1501845256.html (Data obrashhenija: 06.02.2018.)

Esli amerikancy otkljuchat Swift, oni peresjadut s «Boinga» na metlu // EurAsia Daily. 2018. Jan. 27. https://eadaily.com/ru/news/2018/01/27/esli-amerikancy-otklyuchat-swift-oni-peresyadut-sboinga-na-metlu-senator (Data obrashhenija: 06.02.2018.)

Haass R. What the Global Elite Can Learn From Donald Trump // Time. 2018. Jan. 25. URL: http://time.com/5118038/global-elite-donald-trump/ (Data obrashhenija: 06.02.2018.)

Jekonomist: Kitaj gotovit reshitel'nyj shag dlja sverzhenija dollara // Jekspert. 2018. N 6. URL: http://expert.ru/2017/11/20/onil/ (Data obrashhenija: 06.02.2018.)

Krah gegemonii SShA: Strany BRIKS vse zhe otkazhutsja ot dollara // Pravda.Ru. 2017. Aug. 3. URL: https://www.pravda.ru/world/03-08-2017/1344206-gegemony_usa-0/ (Data obrashhenija: 06.02.2018.)

Leonova O.G. BRIKS - vneamerikanskaja zona vzaimodejstvija // Obozrevatel'. 2015. N 1. P. 25-33.

Leonova O.G. Global'naja regionalizacija kak fenomen razvitija global'nogo mira // Vek globalizacii. 2013. N 1. P. 59-66.

Moody's uluchshilo prognoz po kreditnomu rejtingu Rossii do «pozitivnogo»// RBK. 2018. Jan. 26. URL: https://www.rbc.ru/economics/26/01/2018/5a6a575a9a7947595acd7712 (Data obrashhenija: 06.02.2018.)

Vladimir Putin prinjal uchastie v plenarnom zasedanii jubilejnoj 70-j sessii General'noj Assamblei OON v N'ju-Jorke // Oficial'nye setevye resursy Prezidenta Rossii. 2015. Sept. 28. URL: http://www.kremlin.ru/events/president/news/50385 (Data obrashhenija: 06.02.2018.) 